\title{
ANTIDIABETIC, ANTI-INFLAMMATORY, ANTIBACTERIAL, ANTI-HELMINTHIC, ANTIOXIDANT AND NUTRITIONAL POTENTIAL OF MUSA PARADISIACA
}

\author{
OLUWAFEMI OMONIYI OGUNTIBEJU* \\ Department of Biomedical Sciences, Phytomedicine and Phytochemistry Group, Oxidative Stress Research Centre, Faculty of \\ Health and Wellness Sciences, Cape Peninsula University of Technology, Bellville 7535, South Africa.
}

Email: oguntibejuo@cput.ac.za

Received: 21 May 2019, Revised and Accepted: 31 July 2019

ABSTRACT

The medicinal and economic values of medicinal plants remain vital to the well-being, growth, and development of humans, especially those living in developing countries. It has been shown that due to the availability, less side effects, general acceptance by local people, medicinal plants contribute significantly to improving health-care delivery system by supplying important pharmaceutical and pharmacological ingredients that are affordable to the teaming majority of people. It is estimated that $30 \%$ of pharmaceutical products that are sold globally is rich in compounds derived from plant materials. It is also of interest to report that over $80 \%$ of the people in developing countries, mostly in Asia and Africa depend heavily on plant products in the treatment and management of various disease conditions. The interest in demand and utilization of medicinal plants has also increased significantly due to the high cost of orthodox medications, lack of good transportation, lack of storage facilities, inadequate availability of health professionals, and lack of the will and political power to provide basic health needs for the citizens of these developing countries. Musa paradisiaca is one of such medicinal plants believed to have multi-faceted health benefits and its health benefits extend to different countries of the world. It is a stable crop found in Asia, Africa, and Central and South America commonly consumed as energy-yielding food but with many medicinal values as well. It is used in the treatment and management of diabetes mellitus, inflammation, parasitic infection, microbial infections, renal, and liver dysfunction. This manuscript focuses on the antidiabetic, antioxidant, anti-inflammatory, antimicrobial, anti-helminthic, and nutritional values of M. paradisiaca.

Keywords: Diabetes mellitus, Inflammation, Microbial infection, Parasitic infection, Management, Diseases, Nutrition.

(C) 2019 The Authors. Published by Innovare Academic Sciences Pvt Ltd. This is an open access article under the CC BY license (http://creativecommons. org/licenses/by/4. 0/) DOI: http://dx.doi.org/10.22159/ajpcr.2019.v12i10.34239

\section{INTRODUCTION}

Plants have and continue to play significant roles in the health, nutrition, and development of the human race. In fact, it is believed that humans cannot survive without plants when one considers the reliance of humans on the oxygen that is readily provided by plants. Other people, however, could argue that it is a symbiotic relationship where both parties benefit: While plants provide humans with oxygen, humans, in turn, provide plants with carbon dioxide. However, humans have benefited much more and at times at the detriment of plants. Plants remain major source of food and medicine for humans. Evidence exists in the use of plants in the treatment of various diseases, restoring, and fortifying humans and animals biological systems as commonly practiced in Chinese, Japanese, and African traditional medicine [1-5]. Historically, it is important to remind ourselves that the first documentation of traditional Chinese medicine system of medicine is over 2000 years old and has been reported to enlist over 365 drugs [4,6]. Over 5000 medicinal plants have been documented, and about 1000 are used in clinical practice in China [7]. To highlights, the importance of plants, over 1800 various plant species are used by Ayurvedic and other traditional healers in South Asia [8]. In Africa, humans have been using medicinal plants for centuries, and the demand is even on the increase because of the value attached to plants for medicinal and spiritual uses. It has been reported that seven out of the twenty best products sold in pharmaceutical field, are either from natural products or direct derivatives of natural compounds, generating over US $\$ 20$ billion in revenue per year [9]. It is also interesting to note that there are about 400,000 secondary plant metabolites in the world and about 10,000 of them have been isolated as useful products [10].

Musa paradisiaca (Linn.) is a herbaceous plant measuring up to $9 \mathrm{~m}$ in length with a robust tree-like pseudo-stem, displaying a crown of large elongated oval deep-green leaves up to $365 \mathrm{~cm}$ in length and $61 \mathrm{~cm}$ in width [11]. It belongs to the family Musaceae containing over 200 species; growing in the tropics and subtropics. It is seen as a major crop in Africa, Asia, and Central and South America, consumed as energyyielding food; estimated to provide about 60 million people in Africa with over 200 calories/day, contributing to their diet, nutrition, and health [12]. There are two commonly known names in the genus Musa (banana and plantain). For instance, plantain is the common name for herbaceous plants of the genus Musa and the fruits produced are used for cooking, in contrast to the soft, sweet banana and it is generally opined that there is no formal botanical distinction between bananas and plantains and that the use of either name (banana or plantain) is based mainly on how the fruits are consumed [13] and that plantains are recognized to belong to the same species as banana [14]. Analysis of ripe and unripe extracts of $M$. paradisiaca shows that it contains carbohydrate, protein, fat, fiber, ash, and moisture. It is also found to provide calcium, potassium, manganese, sodium, zinc, phosphorus, nitrogen, iron, and copper [12,15].

The fruit of $M$ paradisiaca is used in the treatment and management of diabetes mellitus, dysentery, intestinal lesions, diarrhea, hypertension, ulcerative colitis, and as antimicrobial, and antihelmintic agents [16-19]. The medicinal properties are believed to be associated with its constituents such as polysaccharides, lipids, caffeic acid derivatives, flavonoids, iridoid glycosides, terpenoids, alkaloids, and specific organic acids. Its leaves and seeds have been reported to possess wound healing property, anti-inflammatory, antioxidant, and immune-promoting activities [15,20,21].

\section{ANTIDIABETIC ACTIVITY OF M. PARADISIACA}

Medicinal plants are abundantly available in the tropics and subtropics and could be useful sources as direct therapeutic agents, as raw material for semi-synthetic compounds, as plant-derived chemical structures 
serving as model for new synthetic compounds and used as taxonomic biomarkers for the identification of new compounds. It is important to note that medicinal plants including $M$. paradisiaca have contributed to human health and nutrition [22-24]. Various ingredients have been identified from different parts of $M$. paradisiaca and include serotonin, dopamine, flavonoids, quercetin, 3-0-galactoside, leukocyanidin, 3-0-glucoside, 3-0-rhamnosyl glucoside, and acyl steryl glycosides. To investigate the antidiabetic activity of M. paradisiaca, Lakshmi et al. [24], collected different parts of the plant such as the leaves, peels, roots, stems, and ripe fruits and were authenticated by a Botanist. The various parts were extracted, and ethanolic extracts were assessed in a male rat model following induction of diabetes using streptozotocin (STZ). Results of the study showed that only leaves and ripe fruit peels showed promising antidiabetic effects. The ethanolic extract of the leaves and peels demonstrated lowering blood glucose level at $500 \mathrm{mg} / \mathrm{kg}$ body weight in STZ-induced diabetic rats. Other studies [23,25-28] have reported on the antidiabetic activities of $M$. paradisiaca.

In an attempt to contribute to global efforts in reducing the prevalence and burden of diabetes mellitus through different approaches, Iroaganachi et al. [29] investigated the antidiabetic effects of unripe M. paradisiaca in STZ-induced diabetic rats. The unripe plant obtained locally in the Eastern part of Nigeria was scientifically identified by a Botanist at Forestry Department, Michael Okpara University of Agriculture, Umudike. The STZ-induced diabetic rats were divided into three groups (2-4) consisting of six rats per group and the nondiabetic group (Group 1). The rats were fed for 28 days, after which they were sacrificed and blood samples collected for assay. The results indicated that the serum urea and creatinine levels of diabetic control rats increased significantly compared to nondiabetic rats. Diabetic rats (Group 3) fed unripe extract of $M$. paradisiaca showed significant increase in both protein and albumin with decrease in urea and creatinine levels. The authors concluded that treatment of diabetic rats with unripe $M$. paradisiaca extract was effective in reducing serum urea and creatinine levels while increasing protein and albumin levels and thus could play a role in the management of renal dysfunction in diabetic condition.

The use of unripe $M$. paradisiaca in the management of diabetes and hepatic dysfunction in STZ-induced diabetes in rats was assessed by Eleazu and Okafor [30]. The authors reported that intake of unripe extract by diabetic rats resulted in a significant decrease in blood glucose when compared to diabetic control rats; urine glucose and protein decreased with time following treatment with extract of unripe M. paradisiaca. The authors indicated that the study shows the potential of unripe $M$. paradisiaca extract in the management of diabetes and diabetic complications. Famakin et al. [31] assessed the glycemic and antidiabetic property of $M$. paradisiaca-based functional dough meals in an animal model. For this experiment, 40 diabetic male Wistar rats, randomly divided into six groups with seven per group were used. The animals were fed with $M$. paradisiaca-based diet for 28 days and blood glucose levels measured. The result showed that there was a significant reduction in blood glucose level following feeding diabetic animals with M. paradisiaca-based diet for 28 days.

\section{ANTI-INFLAMMATORY ACTIVITY OF M. PARADISIACA}

The inflammatory reaction is designed to protect the biological system from infection and injury by releasing cells and mediators that fight against foreign bodies to prevent infection. However, excessive inflammatory reaction could lead to adverse inflammatory reactions. Inflammation could be classified as acute and chronic; while acute inflammation is the initial stage of inflammation that persists for a short time, chronic inflammation, on the other hand, persists for longer period and depending on the intensity of the inflammation, mediators that are elicited in the affected area could reach the circulation and cause fever $[20,21]$. Inflammation is a complex pathophysiological process, mediated by different signaling molecules [15,32]. To investigate the anti-inflammatory activity of $M$. paradisiaca, Ibegbu et al. [13] collected the root of plantain plant from plantain plantation in Lagos State, Nigeria. To determine the lethal dose 50 for the plantain root extract, preliminary study was performed with a dose of $5000 \mathrm{mg} / \mathrm{kg}$ body weight and no death was reported, showing that the extract is not toxic. For the anti-inflammatory experiment, a total of 45 adult Wistar rats (male and female rats) were used, grouped into nine groups $(n=5)$. The animals were divided into nine groups and received various treatment. The authors reported that aqueous extracts of plantain roots of Musa species demonstrate significant reduction on egg albumin-induced inflammation and that the prevention of inflammation was time and dose-dependent. High anti-inflammatory activity was documented at 20-80 min; while the anti-inflammatory potency decreased from 80 to $120 \mathrm{~min}$. Egg albumin and other potent edematous agents are known to produce inflammation through the release of inflammatory molecules which, in turn, elicit increase vascular permeability, promoting fluid retention in tissues, culminating in edema. The previous study has reported and maintained that plantain root contains aucubin (a glycoside in plantain) which acts as anti-inflammatory, sedative, antiseptic, antiviral, antihistamine, and antirheumatic agent [33]. The presence of apigenin, Vitamins A, C, E, B-complex vitamins and trace elements such as magnesium, calcium, zinc, and selenium in M. paradisiaca has been shown to reduce inflammation reactions [34].

Bindu et al. [35] argues that drugs used in the treatment of inflammation are linked with severe side effects such as gastric irritation, diarrhea, rashes, stomach ulcers, liver, and kidney dysfunction; therefore, it is important to investigate the use of natural products such as medicinal plants such as $M$. paradisiaca and its anti-inflammatory potentials. He and colleagues collected and identified $M$. paradisiaca leaves, extracted it, performed phytochemical screening, assessed its toxicity effects and its anti-inflammatory activity in rat model. In the evaluation of the antiinflammatory activity of $M$. paradisiaca leaf extract, the authors used the carrageenan-induced hind paw edema in Wistar male and female rats divided into four groups $(n=6)$. Following the experiment and analysis of results, the authors noted that $M$. paradisiaca leaf extract at high and low doses produced significant reduction in carrageenaninduced paw edema in the rats and that the anti-inflammatory activity may be related to the presence of flavonoids, phytosterols, and tannins in the extract.

Rao et al. [36] report that inflammatory diseases are of public concern and that the prevalence is on the increase, therefore, as part of the global efforts to find an appropriate and cheaper treatment regime, it is vital to explore other sources including the application of herbal agents. Hence, the authors determined the anti-inflammatory activity of $M$. paradisiaca (fruit and tepal) in macrophage cell line (RAW 264.7). At the end of the experiment, the authors observed that the two parts of $M$. paradisiaca that were tested, demonstrated anti-inflammatory activity.

The anti-inflammatory activities of Musa species were assessed using various approaches: Inhibition of albumin denaturation, protease inhibition, membrane stabilization, heat-induced hemolysis, and hypotonicity-induced hemolysis [37]. Results showed degrees of effective inhibition of inflammation using the afore-mentioned approaches. In respect of these methods, for instance, denaturation of protein is known to cause inflammation in which proteins lose their secondary and tertiary structures in the face of acid, base, organic salt or heat. White blood cells proteinase plays key role in the development of tissue damage during inflammation reactions, and in the study of Saraswathi and Malathi [37], important protection was offered by proteinase inhibitors (Musa species), stabilizing red blood cell membrane as a mechanism of anti-inflammatory impact. It has also been reported that protective effect on hypo-tonic saline-induced red blood cell leakage is known to represent a good index of antiinflammatory activity of any agent with anti-inflammatory potential.

Biswas et al. [38] stated that xylene-induced edema model represents a preliminary approach in the evaluation of the anti-inflammatory 
activity of a plant extract. To conduct the experiment, the authors used Swiss female rats in testing the anti-inflammatory activity of M. paradisiaca and divided them into four groups $(n=6)$, received various treatments for 7 days. He also repeated the experiment using carrageenan-induced rat paw edema and dextran-induced paw edema. In all these experiments, methanolic extract of $M$. paradisiaca showed significant and dose-related anti-inflammatory activity.

\section{ANTI-BACTERIAL ACTIVITY OF M. PARADISIACA}

The discovery and availability of antibiotics were largely welcomed by humans as antibiotics have significantly contributed to the health and well-being of people all over the world. However, resistance to antibiotics by microorganism is of grave public concern, and the problem seems to be growing. Several plants have been used in the treatment of microbial infections due to the fact that these plants contain secondary metabolites with antimicrobial activities [39]. In testing the antimicrobial activity of M. paradisiaca, Karadi et al. [39] used extract from fruit peel and tested the extract against selected bacteria and fungi: Escherichia coli, Staphylococcus aureus, and Pseudomonas aeruginosa; fungi: Candida albicans and Candida tropicalis. The antimicrobial activity was performed using agar diffusion method using a paper disc, and the minimum inhibition concentration was assessed by microdiffusion method using liquid nutrient media with various aliquots of the test materials. According to the authors [39], extract of $M$. paradisiaca at different concentrations produced strong antibacterial activity against Gram-positive organisms with greater zone of inhibition than the Gram-negative bacteria. Extract of $M$. paradisiaca also showed potential inhibitory action against fungal strains that were tested.

Recent reports show an increase in the use of medicinal plants as an alternative medicine to the use of synthetic medications, possiblyprompted by global economic challenge, high cost of synthetic medications, lack of access, and side effects of orthodox medications [40]. Medicinal plants have been used in the treatment of alveolitis following tooth extraction. de Melo Júnior et al. [40] advocates that there is a need for new approach especially the use of medicinal plants in the treatment of alveolitis. To test this, the authors collected medicinal plants including M. paradisiaca. For the experiment, 34 male Wistar rats divided into two groups $(n=10)$ were used. The extraction of the right upper jaw incisor of each tooth was done after the animals were anesthetized. Alveolitis was induced using adrenalin in the socket. In the second stage, biological material from the socket was obtained for identification of the microorganisms. The identified bacteria were used to test the antibacterial activity of the plant extracts, and the authors reported that the plants extract including M. paradisiaca showed antibacterial activity against the tested organisms that were identified and isolated from the sockets.

It is known that medicinal plants are rich in bioactive compounds, being in use for thousands of years as antibacterial agents. Increase in demand coupled with a better understanding of the mechanism of actions of plant-based-bioactive compounds has prompted an increased interest in plant-based antibacterial agents [41]. Padam et al. [41] evaluated the antibacterial activities of various solvent extracts of $M$. paradisiaca and reported that methanolic extract of $M$. paradisiaca shows the best antibacterial activity due to its high concentration of phenols.

Measurement of microbial enzyme activity in the evaluation of ecotoxicological effects of environmental substrates has been documented, and dehydrogenase activity has been commonly applied in such evaluations [42]. To evaluate the antibacterial activity of M. paradisiaca, Alisi et al. [43] examined the inhibition of dehydrogenase activity in pathogenic bacteria isolates by aqueous extracts of M. paradisiaca. In this experiment, dehydrogenase activity was assessed using nutrient broth-glucose-triphenyl tetrazolium chloride (TTC) medium supplemented with varied concentrations of plant extract. The two bacteria (Staphylococcus spp. and Pseudomonas spp.) were tested for their ability to reduce TTC to triphenyl formazan, and result was used to assess antibacterial activity of the plant extract.

\section{ANTI-HELMINTIC ACTIVITY OF M. PARADISIACA}

Helminthic infections are known to induce various disease conditions in humans, animals, and plants, and it has been sown that anti-helminthic agents have side effects on humans, animals, and plants with negative consequences; therefore, people have resulted to the use of medicinal plants in the treatment of parasitic infections [44,45]. Krishna et al. [46] in their evaluation of anti-helminthic activity of M. paradisiaca reported that ethanol extract of the plant was significant in effectively paralyzing and killing earthworm at different concentrations.

In vitro screening of the leaves of $M$. paradisiaca for anti-helmintic activity, the report shows that aqueous and methanolic extracts of the plant displayed anti-helmintic activity by inhibiting hatching of eggs of nematodes and that the activity is dose-dependent with aqueous extract showing strong anti-helmintic activity [47]. This in vitro approach can be very useful in poor resource setting due to the fact it is cheaper, economical, and faster compared to in vivo approach. Due to the costeffectiveness of medicinal plants and the associated products, it has gained wide acceptance in veterinary practice and as rich source of herbal anti-helmintic in animals and human treatment of helminthiasis [48]. In an experiment conducted by Accioly et al. [49], it was shown that some fractions of $M$. paradisiaca displayed good leishmanicidal activity in vitro, suggesting that the use of herbal products can be effective in the treatment of tropical diseases caused by protozoa.

\section{ANTIOXIDANT ACTIVITY OF M. PARADISIACA}

In assessing scavenging potential of $M$. paradisiaca, methanolic, ethanolic, aqueous, and ethyl acetate extracts of $M$. paradisiaca was able to scavenge over $50 \%$ of 2,2-diphenyl-picrylhydrazyl radicals at specific concentrations, showing that extract of the plant displayed strong antioxidant activity [41]. Extracts of $M$. paradisiaca contain significant amount of cyanidin rutinoside-a substantial antioxidant [50]. Yin et al. [51] noted that extract of $M$. paradisiaca significantly reduced plasma oxidative stress. Other scientists such as Imam and Akter [11], Vijayakumar et al. [52] have also documented the antioxidant activity of the extracts of $M$. paradisiaca.

\section{NUTRITIONAL VALUE OF M. PARADISIACA}

M. paradisiaca is a common fruit with global importance in terms of nutritional and economical values, spreading far across 130 countries [53]. It can be eaten raw, fried, cooked, roasted or baked, or processed in different forms such as juice, flour, or puree. Its fruit constitutes a rich source of phytonutrients, vitamins, and phenolic compounds and contains phosphorus, sodium, potassium, zinc, magnesium, copper, calcium, iron as well as the application of $M$. paradisiaca as an ingredient in food products has been reported to contribute positively to human health. Its addition to recipes of various food products has been shown to improve total dietary fiber, resistant, and total starch $[54,55]$. The amount of phenolic compounds and flavonoids differs according to genotypes and locations [56]. Carotenoids identified in $M$. paradisiaca include lutein, beta-carotene, alpha-carotene, violaxanthin, auroxanthin, iso-lutein, neoxanthin, beta-cryptoxanthin, and alpha-cryptoxanthin and the concentration varies with cultivars and their presence in $M$. paradisiaca is known to protect against Vitamin A deficiency [57]. It should be known that the role of carotenoids in reducing the risk of cardiovascular diseases and improving immunity have been reported [58]. A single banana is believed to provide about $23 \%$ of daily need of potassium, helping to maintain proper functioning of the muscles while preventing spasm, promote healthy teeth, bones, tissue, boost immune system, supports healing, growth of tissue, and promotes absorption of calcium [59]. $M$. paradisiaca has also been reported to be used as a remedy for constipation, in the treatment of intestinal lesions and in the management of malnutrition in children [60].

M. paradisiaca has been used in the management of anemia and high blood pressure due to its high iron content and high potassium [60]. 
Serotonin in $M$. paradisiaca is believed to be useful in preventing depression by changing mood, enhancing relation; also that resistant starch present in $M$. paradisiaca is suitable in the diet of individuals with cardiovascular and diabetic problems [61]. A natural flavonoid leukocyanidin is reported to be responsible for anti-ulcerative properties of unripe $M$. paradisiaca and its protective role in gastric mucosa in aspirin-induced erosions [62]. Consumption of $M$. paradisiaca in diets has been reported to reduce fasting blood glucose and low-density lipoprotein (LDL)-cholesterol and liver glycogen [63]. M. paradisiaca is considered as a source of dietary fructo-oligosaccharides and has been reported to reduce the levels of serum cholesterol, improve mineral absorption, stimulate the growth of non-pathogenic intestinal micro-organisms as a result of their prebiotic impact [64] while taken of $M$. paradisiaca on a daily basis improved insulin sensitivity in diabetic patients [65]. Phytosterols present in M. paradisiaca inhibit the absorption of cholesterol from the small intestine by removing it from the micelles and increasing its excretion and are therefore able to decrease the level of serum LDL-cholesterol [66]. Protective effects of M. paradisiaca in the diet of patients with colorectal cancer in control subjects have shown that extract of $M$. paradisiaca demonstrated highest antiangiogenic activity inhibition and was able to inhibit the growth of colon cancer cell line [67].

\section{CONCLUSION AND RECOMMENDATION}

Due to the important role medicinal plants play in the health, nutritional, cultural, traditional and spiritual life of humans, interest in the use of medicinal plants continues to grow. This interest prompted the review of previous studies on the antidiabetic, anti-inflammatory, antibacterial, anti-helmintic, antioxidant, and nutritional properties of $M$. paradisiaca. It is envisaged that the comprehensive information presented in this review paper will enrich the knowledge of the public on the health benefits of the plant and stimulate further research on the plant. Further research to isolate key active ingredients in M. paradisiaca is suggested. There is a need to conduct clinical trials on the antidiabetic, anti-inflammatory, and antioxidant activities of M. paradisiaca in human beings.

\section{ACKNOWLEDGMENTS}

The author is grateful to Cape Peninsula University of Technology and National Research Foundation (South Africa) for financial support.

\section{AUTHOR'S CONTRIBUTIONS}

Oluwafemi Omoniyi Oguntibeju conceptualized the research idea, performed literature search, wrote and edited the manuscript; revised the manuscript and acted as the corresponding author.

\section{CONFLICTS OF INTEREST}

The author declares that there are no conflicts of interest.

\section{REFERENCES}

1. Aslam MS, Ahmad MS. Worldwide importance of medicinal plants: Current and historical perspective. Recent Adv Biol Med 2016;2:88-93.

2. Bukar BB, Dayom DW, Uguru MO. The growing economic importance of medicinal plants and the need for developing countries to harness from it: A mini review. IOSR J Pharm 2016;6:42-52.

3. Oguntibeju OO, Meyer S, Aboua YG, Goboza M. Hypoxis hemerocallidea significantly reduced hyperglycaemia and hyperglycaemic-induced oxidative stress in the liver and kidney tissues of streptozotocin-induced diabetic male Wistar rats. Evid Based Complement Altern Med 2016;2016:1-10.

4. Chen HZ. Current status of blood lipid level and treatment of hyperglycaemia in Chinese population. J Chin Integr Med 2004;2:81-2.

5. Mishra PR, Panda PK, Apanna KC, Panigrahi S. Evaluation of acute hypolipidaemic activity of different plant extracts in triton WR1339-induced hyperlipidaemia in albino rats. Pharmacol Online 2011;3:319-23.

6. Dawit A. Traditional medicine in Ethiopia: The attempt being made to promote it for effective and better utilization. Ethiopia J Sci
1986;9:6269.

7. World Health Organization. Legal Status of Traditional Medicine and Complementary Alternative Medicine: A World-Wide Review. Geneva, Switzerland: World Health Organization; 2001.

8. Zemede A. Ethno-Botany of Nation, Nationalities and Peoples in Gambella, Benishangul-Gumuz and Southern region of Ethiopia. Addis Ababa: Addis Ababa University; 1999. p. 172.

9. Knobel DL, Cleaveland S, Coleman PG, Fèvre EM, Meltzer MI, Miranda ME, et al. Re-evaluating the burden of rabies in Africa and Asia. Bull World Health Organ 2005;83:360-8.

10. World Health Organization. WHO Expert Consultation on Rabies. WHO Technical Report Series, 931. Geneva, Switzerland: World Health Organization; 2005. p. 1-12.

11. Imam MA, Akter S. Musa paradisiaca L. and Musa sapientum L.: A phytochemical and pharmacological review. J Appl Pharm Sci 2011;1:14-20.

12. Ighodaro OM. Evaluation study on Nigerian species of Musa paradisiaca peels: Phytochemical screening, proximate analysis, mineral composition and antimicrobial activities. Researcher 2012;4:17-20.

13. Ibegbu AO, Okonji UJ, Hammah WO, Umana UE, Iyembe DT, Musa SA. Anti-inflammatory effects of the aqueous extracts of plantain roots (Musa species). Br J Pharm Toxicol 2012;3:70-5.

14. Nelson SC, Ploetz RC, Kepler AK. Musa Species (Banana and Plantain) Profiles for Pacific Island Agroforestry; 2006. http://www.agroforestry. net.

15. Vandana I, Gupta AK, Mukerjee A. Phyochemical screening and evaluation of anti-inflammatory activity of aerial part extracts of Plantago major L. Asian J Pharm Clin Res 2017;10:307-11.

16. Okoli RI, Aigbe O, Ohaju-Obodo JO, Mensah JK. Medicinal herbs used for managing some common ailments among Esan people of Edo State, Nigeria. Pak J Nutr 2007;6:490-6.

17. Partha P, Hossain AB. Ethnobotanical investigation into the Mandi ethnic community in Bangladesh. Bangladesh J Plant Taxon 2007; 14:129-45

18. Khare CP. Indian Medicinal Plants. New York, USA: Springer Science; 2007. p. 426

19. Rai PK, Jaiswal D, Rai NK, Pandhija S, Rai AK, Watal G, et al. Role of glycemic elements of Cynodon dactylon and Musa paradisiaca in diabetes management. Lasers Med Sci 2009;24:761-8.

20. Beara IN, Lesjak MM, Jovin ED, Balog KJ, Anackov GT, Orcić DZ, et al. Plantain (Plantago L.) species as novel sources of flavonoid antioxidants. J Agric Food Chem 2009;57:9268-73.

21. Jamilah J, Sharifa R, Sharifah AA. GC-MS analysis of various extracts from leaf of Plantago major used as traditional medicine. World Appl Sci J 2012;17:67-70.

22. Ploetz RC, Kepler AK, Daniels J, Nelson SC. Banana and plantainan overview with emphasis on Pacific Island cultivars. Agro For Vet 2007; $1: 1-27$

23. Virginia DK, Luisa HC, Danielle FP, Barbara GP, Femanda AM, Ziliani S, et al. Beneficial effects of banana leaves (Musa paradisiaca) on glucose homeostasis: Multiple sites of action. Rev Bras Phramacogn 2013;23:706-15.

24. Lakshmi SK, Agarwal SK, Ansari AJ, Mahdi AA, Srivastava AK. Antidiabetic potential of Musa paradisiaca in streptozotocin-induced diabetic rats. J Phytopharmacol 2014;3:77-81.

25. Pari L, Umamaheswari J. Antihyperglycaemic activity of Musa sapientum flowers: Effect on lipid peroxidation in alloxan diabetic rats. Phytother Res 2000;14:136-8.

26. Ojewole JA, Adewunmi CO. Hypoglycemic effect of methanolic extract of Musa paradisiaca (Musaceae) green fruits in normal and diabetic mice. Methods Find Exp Clin Pharmacol 2003;25:453-6.

27. Mohan Kumar M, Joshi MC, Prabha T, Dorababu M, Goel RK. Effect of plantain banana on gastric ulceration in NIDDM rats: Role of gastric mucosal glycoproteins, cell proliferation, antioxidants and free radicals. Indian J Exp Biol 2006;44:292-9.

28. Shanmuga SC, Subramanian S. Biochemical evaluation of hypoglycaemic activity of Musa Paradisiaca flowers in STZ-induced experimental diabetes in rats. Asian J Res Chem 2011;4:827-33.

29. Iroaganachi M, Eleazu C, Okafor P. Effect of unripe plantain (Musa paradisiaca) and ginger (Zingiber officinale) on renal dysfunction in streptozotocin-induced diabetic rats. JOP 2015;16:167-70.

30. Eleazu CO, Okafor P. Use of unripe plantain (Musa paradisiaca) in the management of diabetes and hepatic dysfunction in streptozotocin induced diabetes in rats. Interv Med Appl Sci 2015;7:9-16.

31. Famakin O, Fatoyinbo A, Ijarotimi OS, Badejo AA, Fagbemi TN. Assessment of nutritional quality, glycaemic index, antidiabetic and 
sensory properties of plantain (Musa paradisiaca)-based functional dough meals. J Food Sci Technol 2016;53:3865-75.

32. Franklin PX, Pillai AD, Rathod PD, Yerande S, Nivsarkar M, Padh H, et al. 2-amino-5-thiazolyl motif: A novel scaffold for designing anti-inflammatory agents of diverse structures. Eur J Med Chem 2008;43:129-34.

33. Ahlborn H, Henderson S, Davies N. No immediate pain relief for the pharmaceutical industry. Curr Opin Drug Discov Devel 2005;8:384-91.

34. Adelolu AT, Enesi DO. Assessment of proximate, mineral, vitamin and phytochemical composition of plantain (Musa paradisiaca) bract-an agricultural waste. Int Res J Plant Sci 2013;4:192-7.

35. Bindu HM, Guddeti V, Praveen TK, Surekha LS, Gayathri M, Allam PV, et al. Evaluation of anti-inflammatory activity of Musa paradisiac (Linn) leaves extract in rats. Int Pharm Chem Biol Sci 2014;4:753-7.

36. Rao US, Ahmad BA, Mohd KS. In vitro oxide scavenging and antiinflammatory activities of different solvent extracts of various parts of Musa paradisiaca. Malays J Anal Sci 2016;20:1191-202.

37. Saraswathi RS, Malathi M. In vitro anti-inflammatory activity of different variety of Musa sapientum (banana) peel extract. Int J Curr Res 2017;9:47300-2.

38. Biswas C, Basak D, Chakroverty R, Banerjee A, Dey S, Mazumder UK. Effect of methanol extract of Musa paradisiaca (Linn) stem juice on chemically induced acute inflammation. Int J Pharm Pharm Sci 2012;4:148-50.

39. Karadi RV, Shah A, Parekh P, Azmi P. Antimicrobial activities of Musa paradisiaca and Cocas nucifera. Int Res Pharm Biomed Sci 2011;2:264-7

40. de Melo Júnior EJ, Raposo MJ, Lisboa Neto JA, Diniz MF, Marcelino Júnior CA, Sant'Ana AE, et al. Medicinal plants in the healing of dry socket in rats: Microbiological and microscopic analysis. Phytomedicine 2002;9:109-16.

41. Padam BS, Tin HS, Chye FY, Abdullah MI. Anti-bacterial and antioxidant activities of the various solvent extracts of Musa paradisiaca inflorescences. J Biol Sci 2012;12:62-73.

42. Matthew M, Obbard J. Optimisation of the dehydrogenase assay for measurement of indigenous microbial activity in beach sediments contaminated with petroleum. Biotech Lett 2001;23:227-30.

43. Alisi CS, Nwanyanwu CE, Akujobi CO, Ibegbulem CO. Inhibition of dehydrogenase activity in pathogenic bacteria isolates by aqueous extracts of Musa paradisaca. Afr J Biotech 2008;7:1821-5.

44. Akhtar MS, Zafar I, Khan MN, Muhammad L. Antihelminthic activity of medicinal plants with particular reference to their use in animals in Indo-Pakistan subcontinent. Small Rumin Res 2000;38:99-107.

45. Tambe VD, Nirmal SA, Jadhav RS, Ghogare PB, Bhalke RD. Antihelmintic activity of Wedelia trilobata leaves. Ind J Nat Prod 2006;22:27-9

46. Krishna VV, Kumar KG, Pradeepa K, Kumar SR, Vilay K. Antihelminthic activity of Musa paradisiaca (Linn) cv Puttabale. Int J Pharm Sci Drug Res 2013;5:67-9.

47. Hussain A, Khan MN, Sajid Z, Iqbal MK, Khan RZ, Abbas MA. In vitro screening of the leaves of Musa paradisiaca for anti-helmintic activity. J Anim Plant Sci 2010;20:5-8.

48. Kolodziej H, Kiderlen AF. Antileishmanial activity and immune modulatory effects of tannins and related compounds on Leishmania parasitised RAW 264.7 cells. Phytochemistry 2005;66:2056-71.

49. Accioly MP, Bevilaqua CM, Rondon FC, de Morais SM, Machado LK,
Almeida CA, et al. Leishmanicidal activity in vitro of Musa paradisiaca L. and Spondias mombin L. Fractions. Vet Parasitol 2012;187:79-84

50. Roobha JJ, Saravanakumar M, Aravinthan KM, Devi PS. Antioxidant analysis of anthocyanidin extracted from Musa acuminata bract. J Pharm Res 2011;4:1488-92.

51. Yin X, Quan J, Kanazawa T. Banana prevents plasma oxidative stress in healthy individuals. Plant Foods Hum Nutr 2008;63:71-6.

52. Vijayakumar S, Presannakumar G, Vijayalakshmi NR. Investigations on the effect of flavonoids from banana, Musa paradisiaca L. On lipid metabolism in rats. J Diet Suppl 2009;6:111-23.

53. Singh B, Singh JP, Kaur A, Singh N. Bioactive compounds in banana and their associated health benefits a review. Food Chem 2016;206:1-1.

54. Foster M, Rodriquez ER, Martin JD, Romero CD. Distribution of nutrients in edible banana pulp. Food Tech Biotech 2003;41:167-72.

55. Davey MW, Stals E, Ngoh-Newilah G, Tomekpe K, Lusty C, Markham R, et al. Sampling strategies and variability in fruit pulp micronutrient contents of west and Central African bananas and plantains (Musa species). J Agric Food Chem 2007;55:2633-44.

56. Borges MH,Alves DL, Raslan DS, Piló-Veloso D, Rodrigues VM, HomsiBrandeburgo MI, et al. Neutralizing properties of Musa paradisiaca L. (Musaceae) juice on phospholipase A2, myotoxic, hemorrhagic and lethal activities of crotalidae venoms. J Ethnopharmacol 2005;98:21-9.

57. Beatrice E, Deborah N, Guy B. Provitamin A carotenoid content of unripe and ripe banana cultivars for potential adoption in Easterm Africa. J Food Compost Anal 2015;43:1-6.

58. Krinsky NI, Johnson EJ. Carotenoid actions and their relation to health and disease. Mol Aspects Med 2005;26:459-516.

59. Kumar KS, Bhowmilk D, Duraivel S, Umadeyi M. Traditional and medicinal uses of banana. J Pharmacogn Phytochem 2012;1:2278-4136.

60. Bhaskar JJ. Banana (Musa $\mathrm{sp}$ ) flower and pseudosteim: Dietary fibre and associated antioxidant capacity. J Agric Food Chem 2011;34:28-34.

61. Lassoudere A. Bananier et sa culture. France, Versaillies: CEDEX; 2007.

62. Lewis DA, Fields WN, Shaw GP. A natural flavonoid present in unripe plantain banana pulp (Musa sapientum L. var. Paradisiaca) protects the gastric mucosa from aspirin-induced erosions. J Ethnopharmacol 1999;65:283-8.

63. Usha V, Vijayammal PL, Kurup PA. Effect of dietary fiber from banana (Musa paradisiaca) on cholesterol metabolism. Indian J Exp Biol 1984;22:550-4.

64. Sabater-Molina M, Larqué E, Torrella F, Zamora S. Dietary fructooligosaccharides and potential benefits on health. J Physiol Biochem 2009;65:315-28.

65. Cressey R, Kumsaiyai W, Mangklabruks A. Daily consumption of banana marginally improves blood glucose and lipid profile in hypercholesterolemic subjects and increases serum adiponectin in Type 2 diabetic patients. Indian J Exp Biol 2014;52:1173-81.

66. Thompson GR, Grundy SM. History and development of plant sterol and stanol esters for cholesterol-lowering purposes. Am J Cardiol 2005;96:3D-9.

67. Sen S, Asokkumar K, Umamaheswari M, Sivashanmugam AT, Subhadradevi V. Antiulcerogenic effect of gallic acid in rats and its effect on oxidant and antioxidant parameters in stomach tissue. Indian J Pharm Sci 2013;75:149-55 